\title{
The Impact of Team Reputation and Team Quality on the Loyalty of the Fans of Iranian National Volleyball Team: A Mediating Role of Satisfaction
}

\author{
${ }^{1}$ Alireza Elahi ${ }^{*}$, ${ }^{1}$ Behnam Mahmoudi, ${ }^{1}$ Hossein Akbari Yazdi \\ ${ }^{1}$ Department of Sport Management, Faculty of Sport Science, Kharazmi University, Tehran, Iran.
}

\begin{abstract}
Background. Attention to the loyalty of fans to the long-term success of sports organizations has become increasingly important. On this note, it seems necessary to pay attention to the variables that predict and influence the loyalty of spectators. Objectives. The aim of this study was to determine the mediating role of satisfaction in the effect of team reputation and team quality on the loyalty of the fans of national volleyball team in Iran. Methods. For this reason, five Ponzi et al. (2011) team reputation, Oliver (1980) satisfaction, Mahony (2000) behavioral loyalty, and Zhang et al. (1997) team quality questionnaires were used. Asample of 261 fans that were present at the World League Championship to see the Iranian national volleyball teams were randomly selected and questionnaires were distributed among them. Results. The results of structural equation modeling showed that team quality and team reputation are strong predictors of loyalty of fans $(\beta=0.691, \beta=0.681)$. In addition, the satisfaction of fans has a mediating role in the relationship between team reputation and team quality with loyalty of fans $(\beta=0.043, p<0.05)$. Conclusion. In view of the fact that the impact factor of two team quality and team reputation variables on the loyalty was high, paying attention to these two variables is very important in the formation of loyalty of the fans of the national team of Iran and strong strategies must be devised to achieve this.
\end{abstract}

KEY WORDS: Psychological Commitment, Spectator-Based Reputation, Loyalty, Structural Equation Modeling, Purchase Behavior.

\section{INTRODUCTION}

Fans are one of the most important consumer groups for sports marketers, because watching a sport is recognized as one of the prominent parts of the entertainment industry. Therefore, understanding the attitudes of sports fans is a task and one of the important points of the success of the professionals working in the sports industry (1). On the other hand, paying attention to the loyalty of these sports clients (fans) can be a guarantee of the long-term success of a sports organization. Fans' loyalty is a two-dimensional concept that includes both attitudinal and behavioral dimensions. The attitudinal dimension of fans' loyalty is psychological commitment to a team. So, if fans feel deeply united with their favorite team, if their commitment is constant over time, and if they continue in criticizing, then they will display a high level of psychological commitment $(2,3)$.

Behavioral loyalty dimension also includes frequent behaviors like buying tickets, repeating attendance at a sporting event, watching a contest

*. Corresponding Author:

Alireza Elahi

E-mail: alirezaelahi@yahoo.com 
from television, talking about sports, and shopping sports products of their favorite team (4$6)$. In order to raise the level of fans' loyalty, it is crucial to consider the predictive factors, such as loyal predictors mentioned in various researches. With this in mind, in the field of sport, two variables of team quality and reputation have also been stressed (7-9). In addition, the important variables affecting the loyalty of fans were described.

\section{Team reputation}

The concept of team reputation is the level of customer perception of an organization from the variables that shape this concept, like social responsibility, financial transparency, spectatorbased reputation and so on (7). One of the most important factors affecting fans' loyalty and their continued presence in the stadiums is the reputation of the organization (team), or team reputation, which directly and indirectly affects the valuable outputs of the minds of the customers (fans) such as trust, satisfaction, word of mouth and their loyalty (10-12). A great deal of researches have been carried out on the influence of the reputation of organizations including sports teams, on the loyalty of their customers such as research on Spectator-Based Sports Team Reputation (SSTR) (the reputation of the perception of spectators and fans of the reputation of a sports team). The results of this research have shown that SSTR has positive effects on team identity, trust in the team, and the loyalty of fans $(7,13)$. Other research results have also revealed that the customer-based reputation of the organization can positively affect these factors (loyalty, satisfaction, and word of mouth) $(12,14$, 15). Nguyen and Leblanc (2001) also concluded in their research that the organizational image and organizational reputation had a positive effect on the customer's future tendencies and outcomes. The results of this research on the service organizations have shown that customer loyalty can strengthen the relationship between reputation of the organization and future tendencies of customers and empower this relationship (16). Keh and Xie (2009) also evaluated the mediating role of commitment, trust, and identity of customers among their corporate reputation and customer behavior tendencies, where the role of commitment or, in other words, loyalty of customers has a stronger role in the relationship between reputation and behavioral tendencies such as the loyalty of their customers (10). Some researches stated that the customer-based reputation of organizations has a positive impact on loyalty, trust and customer satisfaction $(14,15)$. What is estimated from the research is that reputation is an intangible variable that sports organizations are likely to ignore, while this variable can have a positive impact on the loyalty of an organization's clients as an intangible asset, so paying attention to it is the necessities of decision making by managers of a sports organization.

\section{Team quality}

Other factors affecting the loyalty of fans can be team quality; team quality refers to the percentage of wins, the number of star players, the percentage of successes, and the quality of a sports team's performance (8). Wakefield and Sloan (1995) noted that fans ("committed spectators") had different behaviors when comparison with less committed fans (17). For example, high-identity fans report their team quality better than lower-identity fans. While some spectators are loyal to one team throughout their lives, other spectators seem to have changed their loyalty due to the unfavorable situation of the team (18). Team quality refers to the total quality of a team in terms of the percentage of wins, team stars, team management, and team star coach (8). There has also been research on team quality and loyalty within the country, the results of which have shown that team quality can be a strong predictor of fan loyalty and team quality can also increase the loyalty of women who favor popular sports teams (19).

Research has also been carried out on the fans of other sports that sometimes have different results, for example, in a study conducted on Australian rugby spectators, a fan's identity, pursuit of sport and the environment were determined as significant predictions for loyalty of fans (6). The team quality is one of the variables that affect the loyalty of fans. This variable can increase the long-term loyalty of fans. When a sports team has star players, star coach and a large percentage of wins, its fans and spectators are very pleased and their positive purchase behavior will increase (6). So, paying attention to the team quality can be a factor affecting the success of a sports team. 


\section{Satisfaction}

Satisfaction is feeling pleasure of organization's customers from the products and services of an organization. On the other hand, loyalty has the most relevance with the satisfaction of the spectators and their reengagement in the competitions (20). The results of a research show that motivation and loyalty have an effect on the relationship between physical features, spectators' satisfaction, and their attendance levels in the competitions (21). Loyalty of fans must be considered as a process and the experience of fans is very important to their team's support. It seems essential to identify the mediating elements in relation to some important variables with the loyalty of fans. Meanwhile, the satisfaction of fans is among the most important mediating variables and the loyalty predictions, and this satisfaction reflects how much they felt positive or negative at the time of their support to their team's performance (22). Other scholars also describe satisfaction as one of the most important predictors of fans' loyalty and the willingness to re-enter the stadium. They are talking about the importance of using affiliate marketing to develop the loyalty of fans and their satisfaction, and in the next stage, positive purchase behaviors (20).

As earlier stated, satisfaction is a strong predictor for fans' loyalty and a willingness to attend the stadium to watch competitions. And those who are satisfied are more likely to buy the tickets of one season. And if loyal fans do not come to the stadiums, there are reasons and they include lack of time and financial resources, because research has proven that loyal fans have the highest average attendance at stadiums and watching competitions (6). Some researchers argue that spectators' satisfaction leads to the behavioral outcomes, such as commitment, willingness to stay, customer retention, the creation of reciprocity between the service provider and the customer, increasing the customer's tolerance to the mistakes in the provision of services, and positive word of mouth. Considering the increasing importance of the quality of services in customer satisfaction and intent to attend, one of the long-term and final goals of the quality of desirable services is to gain spectator loyalty to sporting service organizations $(23,24)$.
As noted earlier, research has proven that many factors can predict loyalty of fans. Also, variables such as satisfaction, in addition to being a strong predictor of loyalty, can play mediating role in the relationship between variables, such as team reputation and team quality on the loyalty of sports fans. One of the research gaps that exists is the lack of attention to the mediating role of important variables, such as the satisfaction of the fans, because identifying the factors affecting loyalty, regardless of mediating variables such as satisfaction, seems to be incomplete. Researchers always point out that satisfaction and fans' loyalty variables are key factors in the success of sports organizations and they believe that loyalty should be the primary goal of marketers and sports managers because these customers (fans) are loyal which lead to long-term survival of sports teams and long-term profit. As stated, it should be aware that in the sports industry and in particular in the Iranian national volleyball team, the understanding and development of fans' satisfaction and subsequently loyalty of fans can increase material and immaterial profits. It can also be a solution to some professional sports problems. Many problems can be reduced by the development of relationships with current and potential fans. Making and maintaining a psychological relationship through long-term loyalty will increase the repurchase rate of team's goods, re-enter the stadium, and positive word of mouth among fans. It is important to note that the sports teams have a very important and influential role in generalizing sport on one hand and promoting professional sports on the other hand. These sports institutions provide the elite athletes for countries and contribute to the achievement of international sports honors. Especially in the field of volleyball, which in recent years has gained significant international and global achievements and has assigned many national funds, identifying the factors affecting the loyalty of the fans of Iranian national volleyball team and mediating factors in maintaining and enhancing this factor (fans' loyalty) should be the requirements of decision making of their managers and marketers. Therefore, this research was conducted to identify the variables affecting the loyalty of fans of the national volleyball team, such as team reputation and quality and the mediating role of 
satisfaction in the relationship between these variables (team reputation and team quality) with the loyalty of the fans addressed. The conceptual framework for the research was designed as shown in Figure 1.

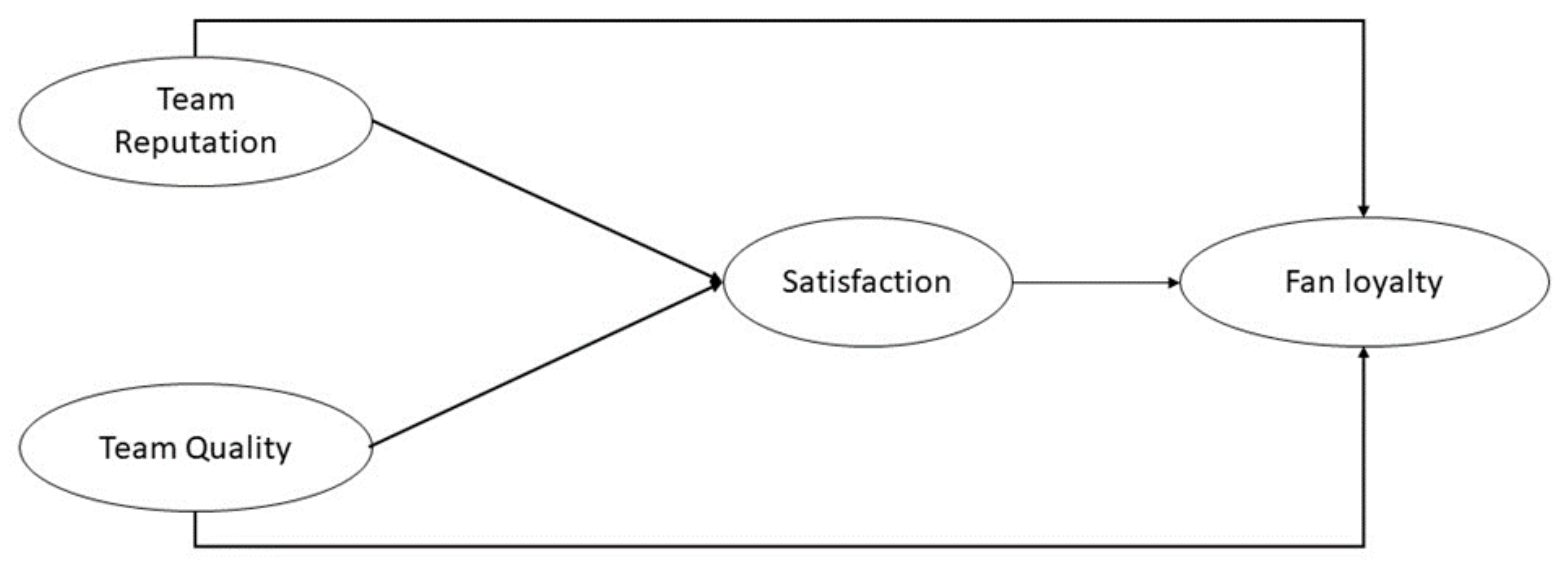

Figure 1. Conceptual model of research.

\section{MATERIALS AND METHODS}

Participants. All the fans of Iranian national volleyball team were chosen as the statistical population of the study. Due to the lack of access to the databases relating to all Iranian national team fans, the fans that were present at Azadi Stadium of Tehran to see world league championship were considered as an accessible and targeted sample.

Research design. At first, the study was conducted in the Iran-Belgium volleyball competition on June 9, 2017 in Azadi Stadium. For this purpose of the study, 100 questionnaires were distributed and then collected after completion. Finally, 39 valid questionnaires were examined and the standard deviation for the preliminary extraction study was set in the Cochran's sample size formula. Based on the results, the minimum number of required samples was estimated to be 260 and in order to reduce the error of measurement, 400 questionnaires were distributed in the three sports of Iran-Serbia, IranArgentina, and Iran-United States on June 10, 2017, June 11, 2017, and June 15, 2017 among volunteer fans. Finally, 261 questionnaires were used and analyzed.

Data collection tool. In order to collect the required data, a personal information form was used to collect the demographic information of the fans of Iranian national volleyball team. Also, the team reputation four-items questionnaire of Ponzi et al. (2011), team quality six-items questionnaire of Zhang et al. (1997), overall satisfaction three-items questionnaire of Oliver (1980), and attitudinal loyalty questionnaire of Mahoony (2000) were used and they were measured using a one-item 5 point scale, ranging from 1 (very likely) to 5 (very unlikely) $(4,25-27)$. It should be noted that before this questionnaire was used on the volleyball fans community, its content validity was assessed by six sports marketing specialists. And the validity of the instrument was measured using a confirmatory factor analysis method. In order to verify the reliability of the questionnaires, a preliminary study was conducted on the fans of volleyball team of Iran and Belgium on June 9, 2017 and the reliability of the questionnaires was obtained to be higher than 0.71 using Cronbach's alpha coefficient.

Statistical Analysis. Kolmogorov-Smirnov test was used to verify the normal distribution of data relating to the variables of the research. In order to analyze the findings, structural equation modeling was applied using LISREL software. In order to analyze the obtained data, two methods of descriptive and inferential statistics were used. To analyze the data, correlation tests, confirmatory factor analysis, and structural equation modeling were used by SPSS and LISREL software. 


\section{RESULTS}

The descriptive findings of the present study showed that more than $70 \%$ of the research samples were single and an average age of 18 to 25 years. Samples of research include $47 \%$ of the spectators with personal cars at the venue for the Iranian national volleyball team. They also selected TV as the best medium (61.7\% average) for news on the Iranian national volleyball team. The results showed that the distribution of data relating to the variables was normal. In order to test the hypothesis of the research, Pearson correlation matrices were drawn between the research variables with the following results:

Table 1. Correlation matrix among variables

\begin{tabular}{ccccc}
\hline & Team Quality & Team Reputation & Satisfaction & loyalty \\
\hline Team Quality & 1 & $0.744^{* *}$ & $0.750^{* *}$ & $0.691^{* *}$ \\
Team Reputation & $0.744^{* *}$ & 1 & $0.727^{* *}$ & $0.681^{* *}$ \\
Satisfaction & $0.750^{* *}$ & $0.727^{* *}$ & 1 & $0.731^{* *}$ \\
Loyalty & $0.691^{* *}$ & $0.681^{* *}$ & $0.681^{* *}$ & 1 \\
\hline
\end{tabular}

${ }^{*}$ Correlation is significant at the 0.01 level (2-tailed).

In order to test the conceptual framework of the research (mediating role of satisfaction in the impact of team reputation and quality on the loyalty of fans of Iranian national volleyball team), structural equations modeling was used. The results are as shown in Figures 2 and 3.

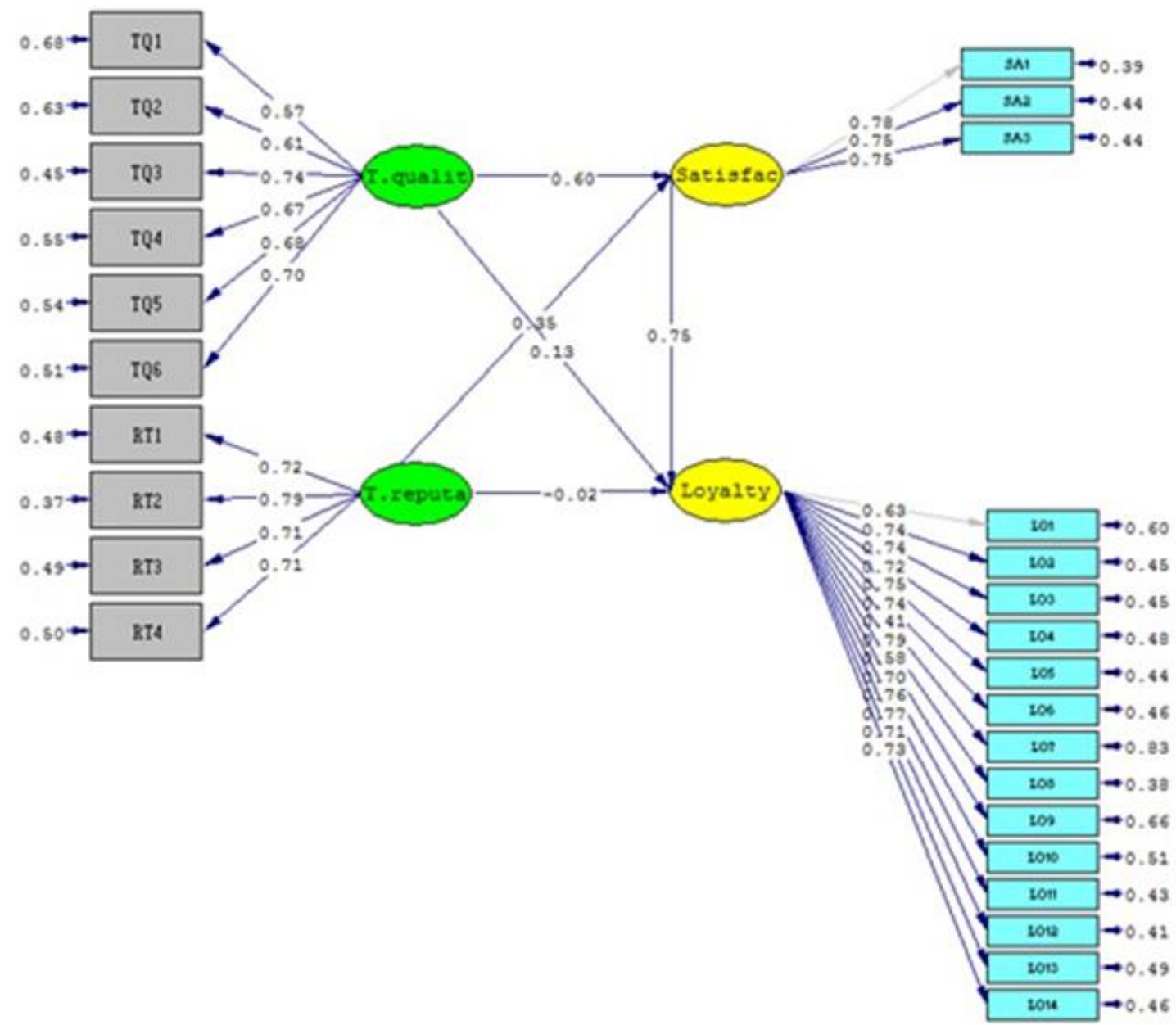

Figure 2. The output of LISREL software in the standard state. Chi-Square=1327.70, $\mathrm{df}=477$, RMSEA 0.069, $\mathrm{p}<0.001$. Figure 2 shows the output of the software to be standard. 


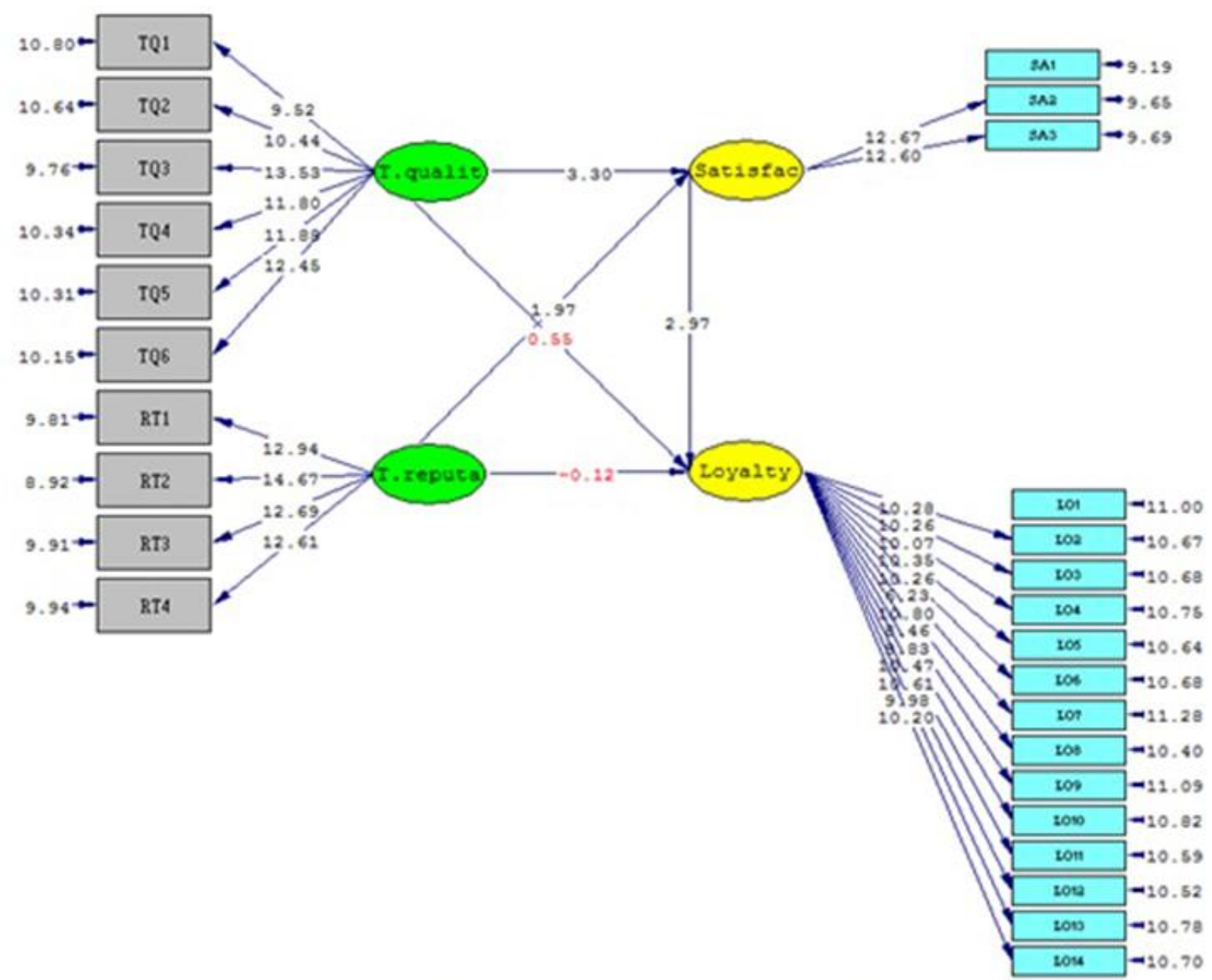

Figure 3. The output of LISREL software in the significant state. Chi-Square=1327.70, $\mathrm{df}=477, \mathrm{RMSEA} 0.069, \mathrm{p}<0.001$.

The results of the output of LISREL software significantly show that the model has good fitting (Chi-Square=1327.70, df =477, RMSEA 0.069).

Considering the significance values ( $\mathrm{t}$ value) of Table 2, which are not in the range of
1.96 to 1.96 , it can be concluded that all the factors of the research are effective. Also, satisfaction plays a mediating role between team reputation and team quality with loyalty of fans.

Table 2. Results of structural equation modeling

\begin{tabular}{ccc}
\hline Fit Index & Domain acceptance Index & Amount achieved \\
\hline $\boldsymbol{x}^{\mathbf{2}} \boldsymbol{/ \boldsymbol { d } \boldsymbol { f }}$ & $<3$ & 2.78 \\
RMSEA & $<0.08$ & 0.069 \\
GFI & $>0.80$ & 0.95 \\
AGFI & $>0.80$ & 0.91 \\
NFI & $>0.90$ & 0.95 \\
RFI & $>0.90$ & 0.95 \\
CFI & $>0.90$ & 0.97 \\
IFI & $>0.90$ & 0.97 \\
\hline
\end{tabular}


Also, according to the LISREL output shown in the in Table 2, the calculated value of is 2.78 and the presence of smaller than 3 represents the appropriate fitting of the model. Also, the approximate root-mean-square error should be less than 0.08 which is equal to 0.069 in the presented model. The value of Goodness of Fit Index (GFI), Adjusted Goodness of Fit Index (AGFI), Normed Fit Index (NFI) and Comparative Fit Index (CFI) components should be higher than 0.9 which is $0.95,0.91,0.95$, and 0.97 , respectively. Also, the RMR value should be less than 0.05 , which is 0.032 in the model. As regards to the indicators and outputs of the LISREL software, it can be said that the data are relatively consistent with the model and the proposed indicators show that, in general, the proposed model is an appropriate model and the empirical data are compatible with it.

\section{DISCUSSION AND CONCLUSION}

Obviously, sports fans play a key role in the success of sports organizations and one of the most important issues in the area of fan management is their loyalty. In general, it can be concluded that loyalty of fans is an important factor for the organization and especially the sports clubs in terms of profitability. Since the Iranian national volleyball team also has a lot of passionate fans, the loyalty of these fans should be one of their most important goals, because the long-term success of any sports club or organization depends on maintaining and increasing their spectators and fans. The model fitted out in this study showed a mediating role of satisfaction in the relationship between team reputation and team quality of Iranian national volleyball team with the loyalty of the fans. Therefore, paying attention to variables such as team quality and reputation can be useful in increasing the customer loyalty including sports fans, because the researchers stated that loyalty of fans in the field of sport is followed by attendance in sports events of favorite team, watching events from television, using media related to the team, buying items for their team and using the colors and symbols of a favorite club. Also, encouraging others to support their favorite team is another important point in displaying behavioral loyalty (28).
Many researchers in the field of sports marketing suggests that in order to maintain and increase the loyalty of fans, sports clubs and organizations should manage the relationship with the fans since the management of the relationship with the fans can help clubs to take advantage of their relationship with them by providing fast and excellent services to the fans. Sports clubs and organizations with accurate identification of their sport customers, including fans can use products and services, message communication and advertising, marketing programs and personal media to communicate with them so that they can maintain their longterm and profitable relationship with them (29).

In the meantime, if loyal fans do not come to the stadiums, there are reasons for that, such as lack of time and financial resources, because research has proven that loyal fans have had the highest average attendance at the stadiums and watching the competitions (30). Therefore, sports organizations such as Iranian national volleyball team and its related factors, such as volleyball federation, should know that their main mission is to maintain and increase the loyalty of fans and they should monitor the manner in which they interact with the fans and they must identify their loyalty factors and improve their performance and marketing programs taking into account the obtained results in order to increase the number of loyal and athletic sports clients committed to sports teams such as national volleyball team. On this note, marketing professors advise organizations to measure their customer satisfaction on a regular basis, because customer satisfaction makes him loyal to the organization.

A satisfied customer is more likely to remain loyal to the organization, welcomes its new products and services, purchases current products, praises organization, its products and services to others, does not pay much attention to its competitors, feels less sensitivity to the prices and imposes less costs on the organization by proposing new ideas for improving products and services. High satisfaction of customers has direct relationship with increase in profit and reduction in the risk of failure and it increases the profitability of sports organizations such as the Iranian national volleyball team in long term (29, $31)$. It is necessary to note that researchers always emphasize that in assimilation between two 
variables, mediating variables should always be considered and assimilation between variables is obsolete regardless of mediating variables.

Satisfaction can also be affected by variables such as team reputation and quality and the reason for the loyalty of fans (31). Due to the importance of the satisfaction of sport's customers' in their loyalty and positive behavioral tendencies, one of the long-term and ultimate goals of sports organizations should be the satisfaction of spectators and fans $(23,32)$.

As discussed, one of the variables fitted from predictions and some kind of reasons for the loyalty of the fans of Iranian national volleyball team was team quality. As shown by other research, factors and subsets of team quality such as star players, quality of management and play quality have a positive and significant impact on both attitudinal and behavioral loyalty of fans. In addition, loyal fans will expand the secondary service segment (such as exclusive components, licensed products, club sponsorship ads, and media productions) using original product of sport (competition), which will provide additional revenues for clubs and sports teams (8).

Team quality is also an effective factor in the formation of women's attitudinal loyalty, so paying attention to the team quality in both genders can lead to their loyalty, while this loyalty is a valuable source of other variables, such as positive purchase behaviors(19). As stated earlier, the key to attracting and retaining customers and sports fans is to improve their positive attitude towards team quality. By improving team quality, desirable satisfaction and loyalty are created in customers, and they are more likely to reuse the services of team or sports club including national team of volleyball, and even offer them to others.

In this study, team reputation is among other factors and predictive variables of fans' loyalty of national volleyball team in Iran.

Sport organizations such as Iranian national volleyball team should not only pay special attention to the loyalty of fans and supporters, but also should not overlook the impact of some influential variables, such as reputation on fans' loyalty. Understanding the variables that affects the loyalty of fans and supporters will help sports organizations in the management of maintaining and increasing the presence of fans. The loyal fans are the key to the success of sports organizations, because they deal with behaviors such as frequent ticket purchases and constant attendance at the sport club and they will benefit sports organizations. Although fans' loyalty stems from a mixture of social, cultural, and psychological factors, loyalty will eventually become payable and the survival and profitability of the clubs depend on those payments. Therefore, the attention and engagement of the club with loyal fans is one of the important points of the sports industry and in particular the national volleyball team.

In general, it is important to know the reason why the customer leaves the organization. With the customer leaving, not only future profits will be lost, but when leaving with a bad experience, customers may share this experience with other colleagues, and this may escape to other customers. So, the attention of managers and authorities to the loyalty of sports customers (fans) is very important in the formation of both types of positive and negative word of mouth. Loyal fans also have a lot of incentives to attend stadiums and they can be quite valuable to a sports team because they are more likely to attend more competition, purchase team products, watch competitions on $\mathrm{TV}$, and listen to them through radio (33).

It important to note that when sports customers are loyal to a sports organization, all of the programs, products and services of that organization will be attractive and irreplaceable for them. In fact, a loyal sports customer does not deal with alternative activities in the presence of his favorite team plans such as the matches of that team and in anyway, he/she brings himself to the stadium and venue. In fact, the lack of alternative choices by fans shows that loyal fans are less likely to engage in alternative activities and other entertainments, and are more likely to go to the stadium and watch competitions closely if there are competitions for their favorite team (31).

Generally, understanding variables that affect loyalty may help sports organizations to manage and maintain the presence of fans. Loyal spectators are the key to the success of sports organizations. They exhibit behaviors such as frequent ticket purchases and continuous attendance that benefit sports organizations. If factors that affect this loyalty are recognized and 
developed, they will provide a sustainable competitive advantage for sports organizations (34). Fans are also the most important part of the sporting events. Many club managers need to design their own plans in an environment that reduces their income and increases administrative costs and attracting loyal fans to the stadiums is a good solution for many sports teams, including volleyball teams, in order to increase income and be different from other sports teams.

In order to increase the presence of loyal fans, recognizing factors that have the most impact on the fans is very important for sport marketing. This allows marketers to use effective marketing strategies to target fans. It also allows managers to effectively plan competitions, improve their work and apply new ways to increase the presence of fans and the resulting revenue, so paying attention to the factors affecting the loyalty of fans and understanding important mediating variables such as their satisfaction is among vital goals of any sports team $(3,35)$.

These factors, as shown by the present study, can include team reputation and quality as predictor variables and satisfaction as their mediating variable and considering each of these factors increases the loyalty of the fans. On the other hand, as discussed earlier, the consequences of the loyalty of the fans are diverse and important and whatever the consequences, it will ultimately cost the club and the survival and profit of the sports teams depend on those payments. Therefore, the attention and engagement of the club with the fans is one of the important points of the volleyball industry, which should be given special attention, so that the lack of attention to psychological factors such as loyalty and the sensitivities of fans will cause heavy losses to sports teams, like when a firm loses its customers. Therefore, there should be considerations concerning the relationship between sports teams and in particular Iranian national volleyball team with loyal fans in order to maintain and increase the loyalty in long term.

With the fact that a small number of the samples were women in this study and gender can be a factor affecting loyalty of fans and their satisfaction, it is suggested that future researchers should consider the loyalty and satisfaction of this gender and its consequences in a more comprehensive study, although this variable (gender) can be assessed as a mediating variable in relation to loyalty to the predictions and its implications.

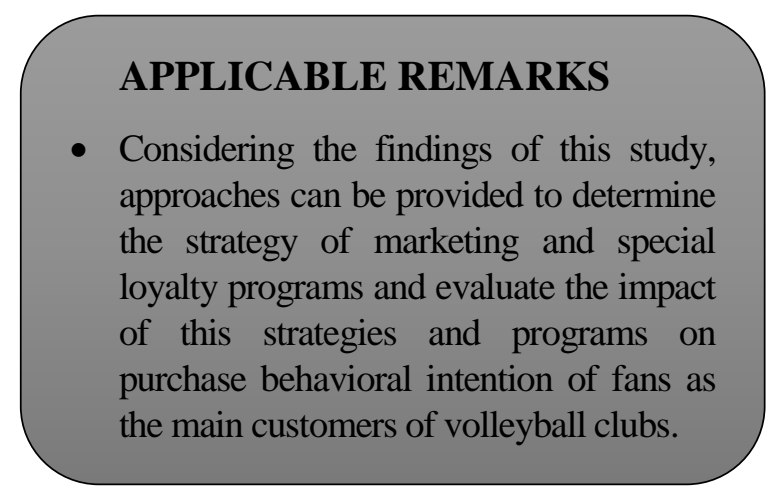

\section{REFERENCES}

1. Lee S. A stady of psychological, sociological, environmental motivation, and loyalty of major and minor league baseball fans 2002.

2. Gladden JM, Funk DC. Understanding Brand Loyalty in Professional Sport: Examining the Link Between Brand Associations and Brand Loyalty. International Journal of Sports Marketing and Sponsorship. 2001;3(1):54-81.

3. Wang RT, Zhang JJ, Tsuji Y. Examining fan motives and loyalty for the Chinese Professional Baseball League of Taiwan. Sport Management Review. 2011;14(4):347-60.

4. Mahony DF, Madrigal R, Howard DA. Using the Psychological Commitment to Team (PCT) Scale to Segment Sport Consumers Based on Loyalty. Sport Marketing Quarterly 2000;9(1):15-25.

5. Sar1 I, Eskiler E, Soyer F. Does Psychological Commitment to Team Enhance Self-esteem? An Easy Way to Raise Self-esteem. International Journal of Humanities and Social Science. 2012;1(19):187-96.

6. Shawn S, Philip JR. The influence of involvement, following sport and fan identification on fan loyalty: an Australian perspective. International Journal of Sports Marketing and Sponsorship. 2012;13(3):57-71.

7. Jang W, Ko YJ, Chan-Olmsted SM. Spectator-based sports team reputation: scale development and validation. International Journal of Sports Marketing and Sponsorship. 2015;16(3):52-72.

8. Yusof A, Lee HS. Spectator Perceptions of Physical Facility and team Quality: A Study of a Malaysian Super League Soccer Match. Research Journal of International Studies. 2008;8:132-40. 
9. Martin CA. Investigating National Football League (NFL) Fan Loyalty. Journal of Marketing Development and Competitiveness. 2013;7(1):42.

10. Keh HT, Xie Y. Corporate reputation and customer behavioral intentions: The roles of trust, identification and commitment. Industrial Marketing Management. 2009;38(7):732-42.

11. Hong SY, Yang S-U. Effects of Reputation, Relational Satisfaction, and Customer-Company Identification on Positive Word-of-Mouth Intentions. Journal of Public Relations Research. 2009;21(4):381-403.

12. Walsh G, Beatty SE. Customer-based corporate reputation of a service firm: scale development and validation. Journal of the Academy of Marketing Science. 2007;35(1):127-43.

13. Walsh G, Mitchell VW, Jackson PR, Beatty SE. Examining the antecedents and consequences of corporate reputation: A customer perspective. British Journal of Management. 2009;20(2):187-203.

14. Shruti M. Relationship of customer based corporate reputation and customer perceived value-A case of automobile sector. International Journal of Computing and Corporate Research. 2015;5(1).

15. Gul R. The Relationship between Reputation, Customer Satisfaction, Trust, and Loyalty. Journal of Public Administration and Governance. 2014;4(3):368-87.

16. Nguyen N, Leblanc G. Corporate image and corporate reputation in customers' retention decisions in services. Journal of Retailing and Consumer Services. 2001;8(4):227-36.

17. Wakefield KL, Sloan HJ. The Effects of Team Loyalty and Selected 8taa Factors on Spectator Attendance. Journal of sport management. 1995;9(2):153-72.

18. Mahony DF, Madrigal R. The Effect of Individual Levels of Self-Monitoring on Loyalty to Professional Football Teams. International Journal of Sports Marketing and Sponsorship. 1999;1(2):36-57.

19. TaheriKia M, Asadzadeh A, Elahi AR. Prediction of Attitudinal and Behavioral loyalty of Esteghlal and Persepolis Fans by Considering the Team Quality: A Case Study of Female Students in Tehran Universities. Journal of Research in Sport Management and Motor Behavior. 2017;In Press.

20. Theysohn S, Hinz O, Nosworthy S, Kirchner M. Official supporters clubs: the untapped potential of fan loyalty. International Journal of Sports Marketing and Sponsorship. 2009;10(4):33-55.

21. Popa A, Yusof A, Shah PM, Geok SK. Sport spectatorship motives of Malaysian university students. International Journal of Sport Studies. 2013;3(2):199-204.

22. Zhang X-x, Liu L, Zhao X, Zheng J, Yang M, Zhang J-q. Towards a Three-Component Model of Fan Loyalty: A Case Study of Chinese Youth. PLOS ONE. 2015;10(4):e0124312.

23. Tsiotsou RH. Sport team loyalty: integrating relationship marketing and a hierarchy of effects. Journal of Services Marketing. 2013;27(6):458-71.

24. Tzetzis G, Alexandris K, Kapsampeli S. Predicting visitors' satisfaction and behavioral intentions from service quality in the context of a small-scale outdoor sport event. International Journal of Event and Festival Management. 2014;5(1):4-21.

25. Ponzi LJ, Fombrun CJ, Gardberg NA. RepTrak ${ }^{\mathrm{TM}}$ pulse: Conceptualizing and validating a short-form measure of corporate reputation. Corporate Reputation Review. 2011;14(1):15-35.

26. Oliver RL. A conceptual model of service quality and servise satisfaction. Advances in services marketing management. 1980;2:65-85.

27. Zhang JJ, Pease DG, Smith DW, Lee JT, Lam ETC, Jambor EA. Factors affecting the decision marking of spectators to attend minor league hockey games. International Sports Journal. 1997;1(1):39-53.

28. Funk D, Pastore DL. Equating attitudes to allegiance: The usefulness of selected attitudinal information in segmenting loyalty to professional sports teams. Sport Marketing Quarterly. 2000;9(4):51-67

29. Kotler P, L. KK. Marketing Management: Prentice Hall; 2014.

30. Tapp A. The loyalty of football fans - We'll support you evermore? Journal of Database Marketing \& Customer Strategy Management. 2004;11(3):203-15.

31. Echchakoui S. Relationship between sales force reputation and customer behavior: Role of experiential value added by sales force. Journal of Retailing and Consumer Services. 2016;28:54-66.

32. Avourdiadou S, Laios A, Kosta G, Theodorakis N. The Relationship of Service Quality Dimensions with the Overall Satisfaction among Participants from Different Experience Levels. Journal of sports and recreation management. 2014;11(1):1-13.

33. Yoshida M, James JD. Customer SatisfactionWith Game and Service Experiences: Antecedents and Consequences. Journal of Sport Management. 2010;24(3):338-61.

34. Bee CC, Havitz ME. Exploring the relationship between involvement, fan attraction, psychological commitment and behavioural loyalty in a sports spectator context. International Journal of Sports Marketing and Sponsorship. 2010;11(2):37-54.

35. Achen RM. Relationship Marketing in United States Professional Sport: Attitudes, Opinions, and Viewpoints of Sport Professionals. Global Sport Business Journal. 2014;2(3):14-27.

Elahi, A., Mahmoudi, B., Akbari Yazdi, H. (2018). Ann Appl Sport Sci, 6(4): 39-48. 